\title{
Gender Differences in Factors Associated with Suicidal Ideation and Depressive Symptoms among Middle-aged Workers in Japan
}

\author{
Norio SUGAWARA ${ }^{1,2} *$, Norio YASUI-FURUKORI ${ }^{1}$, Giro SASAKI ${ }^{2}$, Osamu TANAKA $^{1}$, \\ Takashi UMEDA $^{3}$, Ippei TAKAHASHI ${ }^{3}$, Kazuma DANJO ${ }^{3}$, Masashi MATSUZAKA ${ }^{3}$, \\ Sunao KANEKO ${ }^{1}$ and Shigeyuki NAKAJ ${ }^{2,3}$ \\ ${ }^{1}$ Department of Neuropsychiatry, Hirosaki University School of Medicine, Japan \\ ${ }^{2}$ Aomori Occupational Health Promotion Center, Japan \\ ${ }^{3}$ Department of Social Medicine, Hirosaki University School of Medicine, Japan
}

Received January 9, 2012 and accepted October 24, 2012

Published online in J-STAGE December 26, 2012

\begin{abstract}
The purpose of this study was to assess middle-aged Japanese workers for possible gender differences in the risk factors associated with depressive symptoms and suicidal ideation. 5,878 workers (40-60 yr of age) (3,631 males and 2,247 females) were recruited from randomly selected companies in northern Japan. Demographic and lifestyle factors, suicidal ideation rate, and the data for the Brief Job Stress Questionnaire (BJSQ) and the Center for Epidemiologic Studies for Depression scale (CES-D) were obtained from the self-report questionnaires. After adjusting for possible confounding variables, marital status, absent of stress reduction technique and low job compatibility were significant independent risk factors for suicidal ideation among males. In females, marital status, feeling of insufficient sleep and absence of stress reduction techniques were significant independent risk factors after adjusting for all variables. Under the same adjustments, temporary employment also showed a protective effect against female suicidal ideation. In conclusion, our results suggest that factors related to suicidal ideation differed by gender. Different approaches for each gender might be useful in the development of suicide prevention programs. However, interpretation of work-related effects, such as temporary employment, interpersonal conflict and transportation industry, was hampered by lack of data concerning personal income, working hours and organizational commitment. Additional studies are needed to examine the longitudinal relationships between the risk factors associated with suicidal ideation and depressive symptoms.
\end{abstract}

Key words: Suicidal ideation, Depressive symptoms, Middle-aged workers, Gender difference

\section{Introduction}

Suicide became a major public health concern in the sustained economic recession of the 1990s. In Japan, the

*To whom correspondence should be addressed.

E-mail: nsuga3@yahoo.co.jp

(C)2013 National Institute of Occupational Safety and Health annual number of suicide deaths was 24,391 in 1997 , increased to 32,863 in 1998 , and has since risen over $30,000^{1)}$. The increase in suicide cases is especially prevalent among middle-aged working males ${ }^{2)}$. In 1998, the increased incidence of suicide among middle-aged males caused the average male life expectancy to drop for the first time since the Second World War.

Suicidal ideation is considered to be part of a continuum 
that culminates in suicide attempts and completed suicides. These behaviors are linked to the same risk factors, with variations more likely to occur in the degree rather than in the type of risk factor ${ }^{3-5}$. Previous studies have shown that suicidal ideation is a powerful predictor of completed suicide $^{6,7)}$. Knowledge of the risk factors for suicidal ideation is important in suicide prevention.

In general, females are more likely to report suicidal ideation than males ${ }^{8,}$. . However, the inverse findings have also been reported with regard to gender differences in completed suicide versus suicidal ideation ${ }^{10,11)}$. In addition, previous study showed that depersonalization was found to be risk factor for suicidal ideation in males with depression, whereas derealization and depressive moods posed the major risk in females ${ }^{8)}$. This discrepancy may be related to behavioral differences between males and females, and investigations focusing on gender differences could contribute to measures of mental health problems.

More than $90 \%$ of suicide victims were diagnosed as having psychiatric problems at the time of their death, and approximately two-thirds were diagnosed as having depression ${ }^{12,13)}$. Depression has been identified as the major risk factor for suicidal ideation, suicide attempts, and successful suicide ${ }^{14-16)}$. Because of the strong relationship between suicidal behavior and depression, screening and treatment for depressive disorder has been proposed for the prevention of suicide ${ }^{17)}$.

Previous studies have reported that suicidal ideation and depression were related to several potential factors, including lifestyle, job stress, and socio-demographic background $^{18,19)}$. However, there have been limited evidences focusing on this gender difference ${ }^{18-20)}$. Different patterns based on gender might result in gender specific indicators of suicidal ideation and depression. Therefore, the objectives of this investigation were as follows: (1) to evaluate the relationships between lifestyle factors, job stress and suicidal ideation among middle-aged workers, and (2) to examine the gender specific contributions of lifestyle factors and job stress in the prediction of depressive symptoms and suicidal ideation.

\section{Subjetcs and Methods}

\section{Participants}

The present study was part of a survey conducted by the Aomori Occupational Health Promotion Center in 2004. Aomori Prefecture is located in northern Japan. Annual suicide mortality rates in Japan or the Aomori Prefecture in 2005 were 24.2 completed suicide (male 31.6, female
10.7 ) or 36.8 completed suicide (male 52.2, female 11.8) per 100,000 residents, respectively. In 2005, the Aomori Prefecture recorded the highest male suicide mortality rate in Japan.

The current study is a cross-sectional study of middle aged workers (40 to $60 \mathrm{yt}$ of age) recruited from companies in the Aomori Prefecture. Self-report questionnaire packages were mailed to 764 randomly selected companies that agreed to participate, and were distributed amongst 18,661 workers. Responses were obtained from 9,205 workers. 5,878 workers (3,631 males and 2,247 females) completed questionnaire packages (response rate $31.5 \%$ ).

Participants completed anonymous questionnaires that asked about their sociodemographic background (gender, age, marital status) and their life style factors (living condition, smoking status, habitual alcohol intake, sleep and stress reduction technique). Living condition was categorized as follows: living with family, alone, or others. Smoking status was classified as current smoking or others. Regarding the habitual alcohol intake, respondents were asked to answer the frequency of alcohol intake. Those answering " 1 and more times per week" were included in the "habitual alcohol intake" group, while those answering "Not at all" or "several times per year" were considered the "no habitual alcohol intake" group. Regarding the feeling of insufficient sleep, respondents were asked to answer the sleep condition. Those answering "I can sleep soundly" were included in the "None" group, while those answering "Sometimes I cannot sleep" and "I cannot sleep enough", were considered the "Sometimes" and "Strong" group respectively. Stress reduction technique was evaluated on the basis of responses ("yes" or "no") to the following questions: "Do you have stress reduction technique?"

The investigation was approved by the Aomori Occupational Health Promotion Center as part of the prefecture enterprise. Informed consent was collected from all subjects prior to questionnaire administration, and they were allowed to refuse to answer any questions as they so desired.

\section{Assessment of occupational factors}

Job-related stress was assessed by the Brief Job Stress Questionnaire (BJSQ). The BJSQ was created to identify employees who have mental problems at an early stage ${ }^{21)}$. We used the simple scoring method of Harada and colleagues ${ }^{22)}$.

The questions about the level of job demand were: 1) You have to do an enormous amount of work, 2) You 
cannot complete all your work in the allotted of time, 3) You have to work very hard, 4) You have to focus your attention quite a lot, 5) You do a difficult job that requires a high level of knowledge and skill, 6) You have to constantly think about the work during your work hours, 7) You do a lot of physical work. The questions on the level of job control were: 8) You can work at your own pace, 9) You can decide the order in which you do your work and the way you do it, 10) You can reflect your own opinions on the workplace's work strategy. The questions about interpersonal conflicts were: 12) There are differences of opinion within my department, 13) My department does not get on well with other departments, 14) The atmosphere in my workplace is friendly. The questions concerning job compatibility were: 11) I do not often use my own skills and knowledge in my job, 16) The content of my work suits me, and 17) I have job satisfaction in my work.

For questions regarding the level of job demand and compatibility, we tallied the number of items to which the subject had replied "Yes" or "Yes, to some extent". For questions regarding the level of job control and interpersonal conflicts, we tallied the number of items to which the subject had replied "No" or "Not really". Job demand was defined as an unfavorable condition when six or more questions on job demand were ticked by participants. Job control, interpersonal conflicts and job compatibility were defined as an unfavorable condition when two or more questions on job demand were ticked for each item.

Participants were also asked to respond to several questions related to their type of employment, the industrial classification of their company, and their duration of employment.

\section{Assessment of depressive symptoms and suicidal ideation}

The Japanese version of the Center for Epidemiologic Studies for Depression scale (CES-D) was administered to all participants to measure their depressive status ${ }^{23}$, 24). The questionnaire has been widely used to measure depressive symptoms in community populations and is also used as a screening tool for depression ${ }^{25)}$. The CES-D is a 20 -item self-report measure that focuses on depressive symptoms within the week prior to the administration of the questionnaire. Higher scores indicate an increasing severity of depression, and the maximum score was set at 60 . The traditional cut-off score of 16 has led to nearly $30 \%$ of the Japanese adult population $(35.7 \%$ of the current participants) being defined as depressed, indicating an overestimate of the prevalence of depression compared with Western countries. Therefore, the present study set a higher cut-off score of 19 to define probable depression (CES-D-19 depression), based on a recent validation study ${ }^{26)}$.

Because the CES-D does not directly ask about suicide, the following original item was added to measure suicidal ideation: "Have you ever been severely depressed and thought about suicide?" The responses were made on a four-point scale that ranged from 0 to 3 , with " 0 " indicating that suicidal ideation was present "rarely or none of the time" and " 3 ", indicating that suicidal ideation was present "always".

\section{Statistical analysis}

The data are presented as the mean $\pm \mathrm{SD}$. A value of $p<0.05$ was considered to be statistically significant. Gender comparisons were analyzed using unpaired Student's $t$-tests. $\chi^{2}$ tests or Fisher's exact-tests compared categorical variables between genders. Logistic regression analysis was used to predict probable depression and suicidal ideation. In the model for probable depression, following parameters were included: age, marital status, living condition, habitual alcohol intake, current smoking habit, feeling of insufficient sleep, stress reduction techniques, type of employment, industrial classification, duration of employment, job demand, job control, interpersonal conflicts and job compatibility. In the model for suicidal ideation, further adjustment was made for probable depression as this measure has a direct effect on suicidal ideation. Odds ratios were calculated with $95 \%$ confidence intervals from the univariate analyses and the multivariate logistic regression analyses. The distribution of the suicidal ideation score was extremely skewed, and no transformation normalized this variable. To perform the logistic regression analyses, the suicidal ideation variable was dichotomized into 0 , indicating that suicidal ideation did not occur (scale or item score $=0$ ) or 1 , indicating that suicidal ideation occurred (scale or item score $>0$ ). The data were analyzed using the PASW Statistics PC software for Windows, Version 18.0.0 (SPSS Inc., Chicago, IL, USA).

\section{Results}

\section{Characteristics of participants}

Table 1 shows the gender differences in sociodemographic and occupational factors. According to the optimal CES-D cut-off point of 19, as identified by Wada and colleagues $^{26)}$ for identifying possible cases of depression among working individuals, the frequency of probable 
Table 1. Gender differences in sociodemographic and occupational factors

\begin{tabular}{|c|c|c|c|c|c|c|c|c|}
\hline & & \multicolumn{2}{|c|}{ Male } & \multicolumn{2}{|c|}{ Female } & \multirow{2}{*}{$\mathrm{p}$} & \multicolumn{2}{|c|}{ total } \\
\hline & & $\mathrm{n}$ & $\%$ & $\mathrm{n}$ & $\%$ & & $\mathrm{n}$ & $\%$ \\
\hline \multirow[t]{2}{*}{ Age (years of age) } & $40-49$ & 1,810 & 49.8 & 1,271 & 56.6 & $p<0.001$ & 3,081 & 52.4 \\
\hline & $50-60$ & 1,821 & 50.2 & 976 & 43.4 & & 2,797 & 47.6 \\
\hline \multirow[t]{3}{*}{ Marital Status } & Married & 3,080 & 84.8 & 1,719 & 76.5 & $p<0.001$ & 4,799 & 81.6 \\
\hline & Single & 367 & 10.1 & 169 & 7.5 & & 536 & 9.1 \\
\hline & Widows\&Divorced & 184 & 5.1 & 359 & 16.0 & & 543 & 9.2 \\
\hline \multirow[t]{3}{*}{ Living Condition } & Living with family & 3,252 & 89.6 & 1,971 & 87.7 & $p<0.01$ & 5,223 & 88.9 \\
\hline & Alone & 276 & 7.6 & 170 & 7.6 & & 446 & 7.6 \\
\hline & Others & 103 & 2.8 & 106 & 4.7 & & 209 & 3.6 \\
\hline \multirow[t]{2}{*}{ Habitual alcohol intake } & Yes & 2,919 & 80.4 & 892 & 39.7 & $p<0.001$ & 3,811 & 64.8 \\
\hline & No & 712 & 19.6 & 1,355 & 60.3 & & 2,067 & 35.2 \\
\hline \multirow[t]{2}{*}{ Current smoking habit } & Yes & 2,065 & 56.9 & 544 & 24.2 & $p<0.001$ & 2,609 & 44.4 \\
\hline & No & 1,566 & 43.1 & 1,703 & 75.8 & & 3,269 & 55.6 \\
\hline \multirow[t]{3}{*}{ Feeling of insufficient sleep } & None & 1,969 & 54.2 & 1,120 & 49.8 & $p<0.01$ & 3,089 & 52.6 \\
\hline & Sometimes & 1,566 & 43.1 & 1,064 & 47.4 & & 2,630 & 44.7 \\
\hline & Strong & 96 & 2.6 & 63 & 2.8 & & 159 & 2.7 \\
\hline \multirow[t]{2}{*}{ Stress reduction technique } & Present & 3,237 & 89.1 & 1,938 & 86.2 & $p<0.01$ & 5,175 & 88.0 \\
\hline & Absent & 394 & 10.9 & 309 & 13.8 & & 703 & 12.0 \\
\hline \multirow[t]{2}{*}{ Type of Employment } & Regular & 3,358 & 92.5 & 1,263 & 56.2 & $p<0.001$ & 4,621 & 78.6 \\
\hline & Temporary & 273 & 7.5 & 984 & 43.8 & & 1,257 & 21.4 \\
\hline \multirow[t]{7}{*}{ Industrial Classification } & Manufacturing & 798 & 22.0 & 335 & 14.9 & $p<0.001$ & 1,133 & 19.3 \\
\hline & Construction & 677 & 18.6 & 85 & 3.8 & & 762 & 13.0 \\
\hline & Transportation & 359 & 9.9 & 25 & 1.1 & & 384 & 6.5 \\
\hline & $\begin{array}{l}\text { Wholesale and } \\
\text { retail trade }\end{array}$ & 190 & 5.2 & 202 & 9.0 & & 392 & 6.7 \\
\hline & $\begin{array}{l}\text { Finance and } \\
\text { insurance }\end{array}$ & 105 & 2.9 & 68 & 3.0 & & 173 & 2.9 \\
\hline & Service Industry & 967 & 26.6 & 1,332 & 59.3 & & 2,299 & 39.1 \\
\hline & Others & 535 & 14.7 & 200 & 8.9 & & 735 & 12.5 \\
\hline \multirow[t]{4}{*}{ Duration of Employment (years) } & -5 & 900 & 24.8 & 875 & 38.9 & $p<0.001$ & 1,775 & 30.2 \\
\hline & $6-10$ & 412 & 11.3 & 434 & 19.3 & & 846 & 14.4 \\
\hline & $11-20$ & 766 & 21.1 & 480 & 21.4 & & 1,246 & 21.2 \\
\hline & $21-$ & 1,553 & 42.8 & 458 & 20.4 & & 2,011 & 34.2 \\
\hline \multirow[t]{2}{*}{ Job demand } & Low & 2,429 & 66.9 & 1,467 & 65.3 & n.s. & 3,896 & 66.3 \\
\hline & High & 1,202 & 33.1 & 780 & 34.7 & & 1,982 & 33.7 \\
\hline \multirow[t]{2}{*}{ Job control } & High & 2,259 & 62.2 & 1,431 & 63.7 & n.s. & 3,690 & 62.8 \\
\hline & Low & 1,372 & 37.8 & 816 & 36.3 & & 2,188 & 37.2 \\
\hline \multirow[t]{2}{*}{ Interpersonal conflicts } & Low & 2,385 & 65.7 & 1,261 & 56.1 & $p<0.001$ & 3,646 & 62.0 \\
\hline & High & 1,246 & 34.3 & 986 & 43.9 & & 2,232 & 38.0 \\
\hline \multirow[t]{2}{*}{ Job compatibility } & High & 2,898 & 79.8 & 1,858 & 82.7 & $p<0.01$ & 4,756 & 80.9 \\
\hline & Low & 733 & 20.2 & 389 & 17.3 & & 1,122 & 19.1 \\
\hline
\end{tabular}

Values are mean $\pm \mathrm{SD}$. Student's unpaired $t$-tests or analyses of variance (ANOVA) were performed. Post hoc comparisons were performed using the Dunnet-test. *: $p<0.05$.

clinical depression in the current sample was $24.2 \%$ in males $(\mathrm{n}=879)$ and $25.4 \%$ in females $(\mathrm{n}=570)(p>0.05)$. Overall, the mean CES-D score was $14.2 \pm 7.8$ for males and $14.5 \pm 7.8$ for females $(p>0.05)$. Table 2 shows responses to the suicidal ideation item ("Have you ever been severely depressed and thought about suicide?"). 
Table 2. Responses, by gender, to the item "Have you ever been severely depressed and thought about the suicide?"

\begin{tabular}{lccc}
\hline & $\begin{array}{c}\text { male } \\
\mathrm{n}=3,631(\%)\end{array}$ & $\begin{array}{c}\text { female } \\
\mathrm{n}=2,247(\%)\end{array}$ & $\begin{array}{c}\text { Total } \\
\mathrm{n}=5,878\end{array}$ \\
\hline 1 Rarely or none of the time & 92.1 & 90.9 & 91.6 \\
2 Sometimes & 5.8 & 7.5 & 6.4 \\
3 Usually & 0.5 & 0.7 & 0.6 \\
4 Almost always & 1.6 & 0.9 & 1.3 \\
\hline
\end{tabular}

\section{Logistic regression analyses}

Results of the logistic regression analysis to assess the effects of lifestyle and occupational factors on depressive symptoms (CES-D-19 depression) are shown in Tables 3 and 4. After adjusting for all variables, marital status (single, and widows \& divorced), living alone, industrial classification (transportation) and high interpersonal conflicts were shown to be significant association with probable depression only in middle-aged male workers. Age of 50-60 yr was shown to be protective factors of probable depression under the same adjustments only in females. The commonly associated factors with probable depression in both gender are as follows: current smoking habit, feeling of insufficient sleep, absence of stress reduction techniques, low job control, and low job compatibility.

Table 5 and Table 6 show the results of the logistic regression analyses that assessed the effects of lifestyle and occupational factors on suicidal ideation. After adjusting for all variables, feeling of insufficient sleep and type of employment (temporary) showed a significant association with suicidal ideation only in middle-aged female workers. The commonly associated factors with suicidal ideation in both gender are as follows: marital status (widows \& divorced), absence of stress reduction techniques and probable depression (CES-D 19 depression).

\section{Discussion}

This study investigated possible gender differences in depressive symptoms and suicidal ideation in Japanese middle aged workers by focusing on gender differences in sociodemographic and occupational factors. In both genders, those individuals with a current smoking habit, feeling of insufficient sleep, absence of stress reduction techniques, low job control and low job compatibility showed more depressive symptoms. Suicidal ideation was associated with marital status (widows \& divorced), absence of stress reduction technique and probable depression in both genders. Significant factors affecting suicidal ideation were feeling of insufficient sleep and type of employment for females.

Our results showed a significant relationship between current smoking habit and depressive symptoms. Although the nature of this relationship remains unclear, a number of epidemiological studies have supported our results ${ }^{27-29)}$. One possible explanation is that depressive mood increases the likelihood that individuals will self-medicate negative emotions by smoking ${ }^{30)}$. Another explanation is that smoking itself leads to depression. This latter hypothesis was supported by the observation that adolescents who smoke are at an increased risk of subsequently developing depression $^{31)}$.

Previous studies have shown a significant relationship between sleep disturbance, depressive symptoms and suicidal ideation ${ }^{18,32,33)}$. Goodwin and Marusic (2008) showed that shortened sleep was associated with a statistically significant increase in the likelihood of suicidal ideation (OR 2.5, 95\% CI 1.6-3.9) and suicidal attempt (OR 3.0, 95\%CI 1.4-6.4), after adjusting for confounding variables in a community population in the $\mathrm{US}^{34)}$. Long working hours could be an independent cause of sleep disturbance ${ }^{35)}$. In addition, certain sleep-focused interventions may be appropriate in the treatment of workers having depressive symptoms and suicidal ideation. Educating workers on basic sleep hygiene may improve the quality of sleep.

Among Japanese workers, Takada and colleagues (2009) showed that the absence of stress reduction techniques was associated with depressive symptoms and suicidal ideation ${ }^{19)}$. Nagase and colleagues (2009) showed that the prevalence of a problem-solving strategy is not different between genders. However various types of gender differences were found with respect to the prevalence of emotion-focused and avoidant strategies ${ }^{36}$. Several previous studies have shown that depression was associated positively with avoidant strategies but negatively with problem-solving strategies in both genders. Some coping strategies that have a negative association with depression and suicidal ideation could be utilized in prevention pro$\operatorname{gram}^{37)}$. 
Table 3. Effects of sociodemographic and occupational factors on depressive symptoms (CES-D-19 depression) in male workers

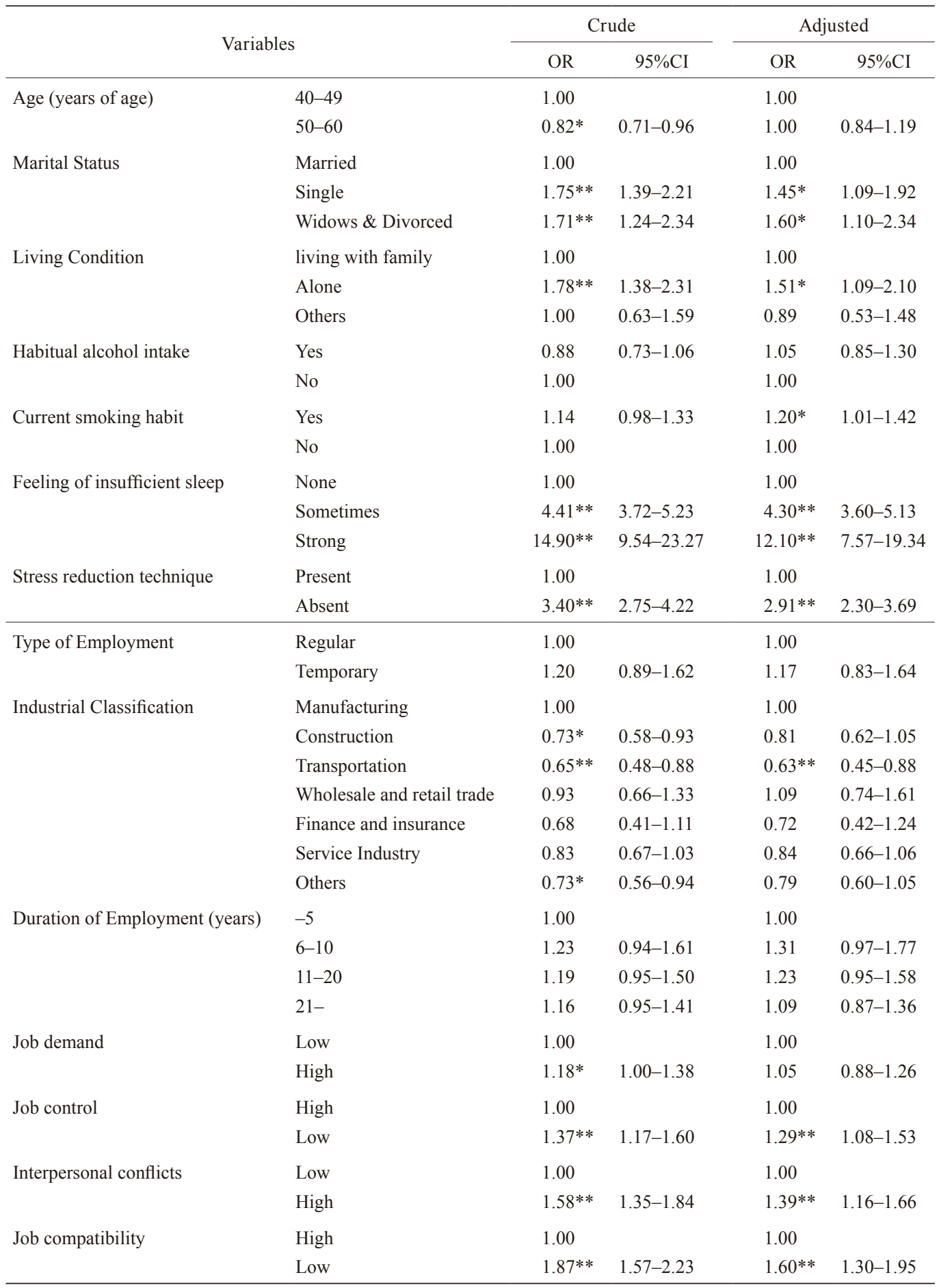

OR: odds ratio, CI: confidence interval, $*: p<0.05, * *: p<0.01$.

Among male workers, interpersonal conflict was highly associated with depression, our findings are consistent with previous studies ${ }^{38,39}$. In this study, more than $40 \%$ of the females were employed on a temporary basis. The workers employed permanently might have greater inter- personal conflicts, and develop depressive symptoms than those employed temporarily.

In this study, our results showed that temporary employment decreased the risk for suicidal ideation in females only. This gender difference may be explained by noting 
Table 4. Effects of sociodemographic and occupational factors on depressive symptoms (CES-D-19 depression) in female workers

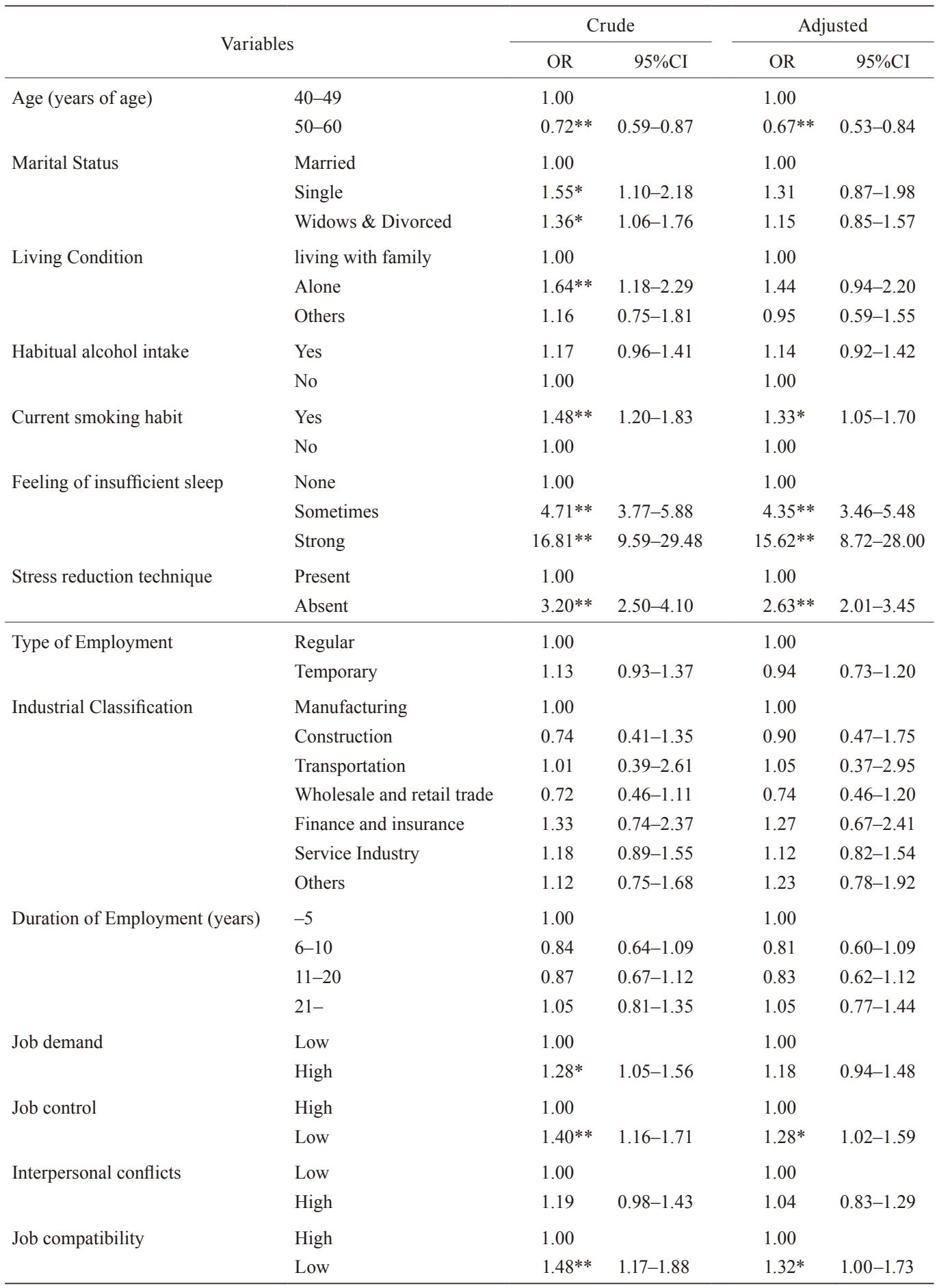

OR: odds ratio, CI: confidence interval, ${ }^{*}: p<0.05, * *: p<0.01$.

that female employees tend to have lower levels of organizational commitment than do their male counter-parts ${ }^{40}$. Japanese males are traditionally conditioned to give priority to their breadwinner role ${ }^{41)}$. Therefore, any job stress might have greater adverse effects on the suicidal ideation of males, compared with females. Another explanation is that difference of average working hours between both gender could affect this discrepancy. Female workers employed on a temporary basis might have shorter working hours than permanently employed ones. 
Table 5. Effects of sociodemographic and occupational factors on suicidal ideation in male workers

\begin{tabular}{|c|c|c|c|c|c|}
\hline \multirow{2}{*}{\multicolumn{2}{|c|}{ Variables }} & \multicolumn{2}{|c|}{ Crude } & \multicolumn{2}{|c|}{ Adjusted } \\
\hline & & \multirow{2}{*}{$\frac{\mathrm{OR}}{1.00}$} & \multirow{2}{*}{$95 \% \mathrm{CI}$} & \multirow{2}{*}{$\frac{\mathrm{OR}}{1.00}$} & \multirow{2}{*}{$95 \% \mathrm{CI}$} \\
\hline Age (years of age) & $40-49$ & & & & \\
\hline & $50-60$ & 0.92 & $0.74-1.20$ & 1.03 & $0.79-1.35$ \\
\hline \multirow[t]{3}{*}{ Marital Status } & Married & 1.00 & & 1.00 & \\
\hline & Single & 1.39 & $0.96-2.01$ & 1.01 & $0.65-1.56$ \\
\hline & Widows \& Divorced & $2.19 * *$ & $1.43-3.37$ & $1.88^{*}$ & $1.12-3.15$ \\
\hline \multirow[t]{3}{*}{ Living Condition } & living with family & 1.00 & & 1.00 & \\
\hline & Alone & $1.60^{*}$ & $1.08-2.37$ & 1.03 & $0.63-1.69$ \\
\hline & Others & 1.17 & $0.58-2.35$ & 1.16 & $0.55-2.44$ \\
\hline \multirow[t]{2}{*}{ Habitual alcohol intake } & Yes & $0.74 *$ & $0.56-0.98$ & 0.79 & $0.58-1.08$ \\
\hline & No & 1.00 & & 1.00 & \\
\hline \multirow[t]{2}{*}{ Current smoking habit } & Yes & 1.00 & $0.78-1.27$ & 0.95 & $0.73-1.23$ \\
\hline & No & 1.00 & & 1.00 & \\
\hline \multirow[t]{3}{*}{ Feeling of insufficient sleep } & None & 1.00 & & 1.00 & \\
\hline & Sometimes & $1.92 * *$ & $1.48-2.48$ & 1.06 & $0.80-1.41$ \\
\hline & Strong & $5.12 * *$ & $3.06-8.57$ & 1.51 & $0.84-2.69$ \\
\hline \multirow[t]{2}{*}{ Stress reduction technique } & Present & 1.00 & & 1.00 & \\
\hline & Absent & $4.22 * *$ & $3.19-5.57$ & $2.79 * *$ & $2.06-3.77$ \\
\hline \multirow[t]{2}{*}{ Type of Employment } & Regular & 1.00 & & 1.00 & \\
\hline & Temporary & 1.03 & $0.65-1.64$ & 1.09 & $0.66-1.82$ \\
\hline \multirow[t]{7}{*}{ Industrial Classification } & Manufacturing & 1.00 & & 1.00 & \\
\hline & Construction & 0.96 & $0.67-1.38$ & 1.16 & $0.78-1.71$ \\
\hline & Transportation & 0.73 & $0.45-1.19$ & 0.79 & $0.47-1.32$ \\
\hline & Wholesale and retail trade & 0.75 & $0.41-1.39$ & 0.77 & $0.40-1.47$ \\
\hline & Finance and insurance & 0.73 & $0.33-1.64$ & 0.86 & $0.36-2.02$ \\
\hline & Service Industry & 0.92 & $0.66-1.29$ & 0.96 & $0.67-1.38$ \\
\hline & Others & 0.70 & $0.46-1.06$ & 0.77 & $0.49-1.21$ \\
\hline \multirow[t]{4}{*}{ Duration of Employment (years) } & -5 & 1.00 & & 1.00 & \\
\hline & $6-10$ & 1.00 & $0.65-1.54$ & 1.03 & $0.74-1.44$ \\
\hline & $11-20$ & 0.96 & $0.67-1.37$ & 0.98 & $0.63-1.51$ \\
\hline & $21-$ & 0.99 & $0.73-1.34$ & 0.94 & $0.66-1.34$ \\
\hline \multirow[t]{2}{*}{ Job demand } & Low & 1.00 & & 1.00 & \\
\hline & High & 1.03 & $0.80-1.34$ & 0.92 & $0.70-1.21$ \\
\hline \multirow[t]{2}{*}{ Job control } & High & 1.00 & & 1.00 & \\
\hline & Low & $1.34^{*}$ & $1.05-1.71$ & 1.2 & $0.92-1.57$ \\
\hline \multirow[t]{2}{*}{ Interpersonal conflicts } & Low & 1.00 & & 1.00 & \\
\hline & High & $1.46^{* *}$ & $1.14-1.87$ & 1.15 & $0.88-1.51$ \\
\hline \multirow[t]{2}{*}{ Job compatibility } & High & 1.00 & & 1.00 & \\
\hline & Low & $1.82 * *$ & $1.39-2.37$ & 1.34 & $0.99-1.81$ \\
\hline \multirow[t]{2}{*}{ CES-D score } & $<19$ & 1.00 & & 1.00 & \\
\hline & $\leq 19$ & $6.26^{* *}$ & $4.86-8.06$ & $4.80 * *$ & $3.61-6.37$ \\
\hline
\end{tabular}

OR: odds ratio, CI: confidence interval, *: $p<0.05, * *: p<0.01$.

Marital status (widows \& divorced) was associated with depressive symptoms and suicidal ideation, consistent with previous studies. Lee and colleagues reported that divorce was a significant risk factor for suicidal ideation among
2054 Taiwanese adults ${ }^{42)}$. Kjoller also showed that suicidal ideation and attempted suicide were more prevalent among single or divorced people in 1362 Danish adults ${ }^{43)}$. In this study, living alone was also associated with depres- 
Table 6. Effects of sociodemographic and occupational factors on suicidal ideation in female workers

\begin{tabular}{|c|c|c|c|c|c|}
\hline \multicolumn{2}{|c|}{ Variables } & \multicolumn{2}{|c|}{ Crude } & \multicolumn{2}{|c|}{ Adjusted } \\
\hline & & \multirow{2}{*}{$\begin{array}{c}\text { OR } \\
1.00\end{array}$} & \multirow[t]{2}{*}{$95 \%$ CI } & \multirow{2}{*}{$\begin{array}{r}\text { OR } \\
1.00\end{array}$} & \multirow[t]{2}{*}{$95 \% \mathrm{CI}$} \\
\hline Age (years of age) & $40-49$ & & & & \\
\hline & $50-60$ & 1.03 & $0.77-1.38$ & 1.16 & $0.83-1.61$ \\
\hline \multirow[t]{3}{*}{ Marital Status } & Married & 1.00 & & 1.00 & \\
\hline & Single & 1.61 & $0.98-2.66$ & 1.49 & $0.83-2.69$ \\
\hline & Widows \& Divorced & $2.04 * *$ & $1.45-2.87$ & $1.78 * *$ & $1.18-2.67$ \\
\hline \multirow{3}{*}{ Living Condition } & living with family & 1.00 & & 1.00 & \\
\hline & Alone & $1.96 * *$ & $1.26-3.07$ & 1.18 & $0.67-2.08$ \\
\hline & Others & 1.39 & $0.75-2.58$ & 1.40 & $0.72-2.72$ \\
\hline \multirow[t]{2}{*}{ Habitual alcohol intake } & Yes & 1.05 & $0.78-1.40$ & 1.08 & $0.78-1.49$ \\
\hline & No & 1.00 & & 1.00 & \\
\hline \multirow{2}{*}{ Current smoking habit } & Yes & $1.38^{*}$ & $1.00-1.89$ & 1.12 & $0.79-1.60$ \\
\hline & No & 1.00 & & 1.00 & \\
\hline \multirow[t]{3}{*}{ Feeling of insufficient sleep } & None & 1.00 & & 1.00 & \\
\hline & Sometimes & $2.23 * *$ & $1.63-3.06$ & 1.30 & $0.92-1.84$ \\
\hline & Strong & $5.71 * *$ & $3.07-10.64$ & $2.25^{*}$ & $1.11-4.58$ \\
\hline \multirow[t]{2}{*}{ Stress reduction technique } & Present & 1.00 & & 1.00 & \\
\hline & Absent & $4.05 * *$ & $2.95-5.57$ & $3.02 * *$ & $2.12-4.28$ \\
\hline \multirow[t]{2}{*}{ Type of Employment } & Regular & 1.00 & & 1.00 & \\
\hline & Temporary & $0.74 *$ & $0.56-0.99$ & $0.66^{*}$ & $0.47-0.93$ \\
\hline \multirow[t]{7}{*}{ Industrial Classification } & Manufacturing & 1.00 & & 1.00 & \\
\hline & Construction & 1.30 & $0.59-2.87$ & 2.05 & $0.87-4.85$ \\
\hline & Transportation & 0.00 & & 0.00 & \\
\hline & Wholesale and retail trade & 0.57 & $0.27-1.20$ & 0.61 & $0.28-1.34$ \\
\hline & Finance and insurance & 0.69 & $0.23-2.02$ & 0.81 & $0.26-2.53$ \\
\hline & Service Industry & 1.25 & $0.82-1.91$ & 1.37 & $0.85-2.19$ \\
\hline & Others & 1.02 & $0.54-1.91$ & 1.28 & $0.65-2.53$ \\
\hline \multirow[t]{4}{*}{ Duration of Employment (years) } & -5 & 1.00 & & 1.00 & \\
\hline & $6-10$ & 0.73 & $0.49-1.11$ & 0.83 & $0.54-1.30$ \\
\hline & $11-20$ & 0.98 & $0.68-1.41$ & 1.12 & $0.74-1.69$ \\
\hline & $21-$ & $0.60^{*}$ & $0.39-0.93$ & 0.65 & $0.40-1.08$ \\
\hline \multirow[t]{2}{*}{ Job demand } & Low & 1.00 & & 1.00 & \\
\hline & High & 1.21 & $0.90-1.63$ & 1.22 & $0.87-1.72$ \\
\hline \multirow[t]{2}{*}{ Job control } & High & 1.00 & & 1.00 & \\
\hline & Low & $1.34 *$ & $1.00-1.80$ & 1.19 & $0.86-1.65$ \\
\hline \multirow[t]{2}{*}{ Interpersonal conflicts } & Low & 1.00 & & 1.00 & \\
\hline & High & 1.03 & $0.77-1.38$ & 0.87 & $0.63-1.20$ \\
\hline \multirow[t]{2}{*}{ Job compatibility } & High & 1.00 & & 1.00 & \\
\hline & Low & 1.14 & $0.79-1.65$ & 0.96 & $0.64-1.45$ \\
\hline \multirow[t]{2}{*}{ CES-D score } & $<19$ & 1.00 & & 1.00 & \\
\hline & $\leq 19$ & $5.06 * *$ & $3.76-6.81$ & $3.61 * *$ & $2.59-5.05$ \\
\hline
\end{tabular}

OR: odds ratio, CI: confidence interval, *: $p<0.05, * *: p<0.01$.

sive symptoms only in males. Support from family and/ or friends could provide workers with the most protection against depression. Previous studies also supported our results ${ }^{19,44,45)}$.
Although transportation industry had been found to involve more dangerous condition ${ }^{46}$, our results showed that transportation industry decreased the risk for depression in male workers only. Previous studies showed that 
transportation industry had associations with depression ${ }^{47}$,

48). Socioeconomic status such as education and personal income might affect our results.

Our study has several limitations. First, our sample population may not have adequately represented the middle-aged workers because the response rate for the survey was only $31.5 \%$. Middle-aged workers who did not participate in our study might have been more likely than those who did participate to exhibit mental health problems. Thus, in the present study, the frequency of suicidal ideation and depressive symptoms could have in fact been underestimated and mental health problems might be more serious among middle-aged workers than was indicated by our results. Second, we could not identify prospective relationships because our study design was cross-sectional. Therefore, the causal effects of sociodemographic and occupational factors on depressive symptoms and suicidal ideation could not be determined. A longitudinal study will be required. Third, responses to our self-report questionnaire may have been influenced by response style, social desirability, and personality factors. Fourth, some important occupational factors such as average working hours, shift work, overtime work, and working schedule irregularity were not included in this study. Fifth, the questionnaire concerning suicidal ideation: "Have you ever been severely depressed and thought about suicide?", asked the life-time prevalence of suicidal ideation and also included lifetime depression as a criteria. The life-time prevalence of suicidal ideation and depression might reflect personality trait that tend to develop depressive symptoms. We could not completely rule out potential misclassification of suicidal ideation that may have affected our results. Further study using validated questionnaire is needed.

The study of suicidal ideation as a dependent variable is essential for suicide prevention. An effective strategy for suicide prevention could be initiated by detecting factors related to depressive symptoms and suicidal ideation from the early stages of suicide contemplation. As our study examined participant responses by gender, age of 50-60 years, marital status, living alone, transportation industry and high interpersonal conflicts were shown to be gender specific factors associated with probable depression. In addition, feeling of insufficient sleep and temporary employment showed a significant association with suicidal ideation only in female workers. However, interpretation of work-related effects, such as temporary employment, interpersonal conflict and transportation industry, was hampered by lack of data concerning personal income, working hours and organizational commitment. Further studies will be necessary to examine the gender specific contributions of job stress in the prediction of depressive symptoms and suicidal ideation.

\section{Acknowledgement}

We are grateful to all the staffs who participated in this study. The authors would also like to express their appreciation to Dr. Hiroichi Tasaki for his help with this study.

\section{References}

1) Ministry of Health, Labor and Welfare, Japan, 2005. Vital statistics. http://www.mhlw.go.jp/toukei/saikin/hw /jinkou/ tokusyu/suicide04/12. html. Accessed June 27, 2011 (in Japanese).

2) Kawakami N (2003) Suicide and suicide prevention in Japan: current status and future directions. J Natl Inst Public Health 52, 254-60 (in Japanese).

3) Brent DA, Perper JA, Goldstein CE, Kolko DJ, Allan MJ, Allman CJ, Zelenak JP (1988) Risk factors for adolescent suicide. A comparison of adolescent suicide victims with suicidal inpatients. Arch Gen Psychiatry 45, 581-8. [Medline] [CrossRef]

4) Kosky R, Silburn S, Zubrick SR (1990) Are children and adolescents who have suicidal thoughts different from those who attempt suicide? J Nerv Ment Dis 178, 38-43. [Medline] [CrossRef]

5) Pelkonen M, Marttunen M, Pulkkinen E, Laippala P, Aro H (1997) Characteristics of out-patient adolescents with suicidal tendencies. Acta Psychiatr Scand 95, 100-7. [Medline] [CrossRef]

6) Beck AT, Steer RA, Kovacs M, Garrison B (1985) Hopelessness and eventual suicide: a 10-year prospective study of patients hospitalized with suicidal ideation. Am J Psychiatry 142, 559-63. [Medline]

7) Hawley CJ, James DV, Birkett PL, Baldwin DS, de Ruiter MJ, Priest RG (1991) Suicidal ideation as a presenting compliant. Associated diagnosis and characteristics in a casualty population. Br J Psychiatry 159, 232-8. [Medline] [CrossRef]

8) Yoshimasu K, Sugahara H, Tokunaga S, Akamine M, Kondo T, Fujisawa K, Miyashita K, Kubo C (2006) Gender differences in psychiatric symptoms related to suicidal ideation in Japanese patients with depression. Psychiatry Clin Neurosci 60, 563-9. [Medline] [CrossRef]

9) Beautrais AL (2002) Gender issues in youth suicidal behaviour. Emerg Med (Fremantle) 14, 35-42. [Medline] [CrossRef]

10) Stein D, Brom D, Elizur A, Witztum E (1998) The association between attitudes toward suicide and suicidal ideation in adolescents. Acta Psychiatr Scand 97, 195-201. [Medline] [CrossRef] 
11) Weissman MM, Bland RC, Canino GJ, Greenwald S, Hwu HG, Joyce PR, Karam EG, Lee CK, Lellouch J, Lepine JP, Newman SC, Rubio-Stipec M, Wells JE, Wickramaratne PJ, Wittchen HU, Yeh EK (1999) Prevalence of suicide ideation and suicide attempts in nine countries. Psychol Med 29, 9-17. [Medline] [CrossRef]

12) Barraclough B, Bunch J, Nelson B, Sainsbury P (1974) A hundred cases of suicide: clinical aspects. Br J Psychiatry 125, 355-73. [Medline] [CrossRef]

13) Isometsä E, Henriksson M, Marttunen M, Heikkinen M, Aro H, Kuoppasalmi K, Lönnqvist J (1995) Mental disorders in young and middle aged men who commit suicide. BMJ 310, 1366-7. [Medline] [CrossRef]

14) Brent DA, Perper JA, Moritz G, Allman C, Friend A, Roth C, Schweers J, Balach L, Baugher M (1993) Psychiatric risk factors for adolescent suicide: a case-control study. J Am Acad Child Adolesc Psychiatry 32, 521-9. [Medline] [CrossRef]

15) Grøholt B, Ekeberg O, Wichstrøm L, Haldorsen T (2000) Young suicide attempters: a comparison between a clinical and an epidemiological sample. J Am Acad Child Adolesc Psychiatry 39, 868-75. [Medline] [CrossRef]

16) Turvey CL, Conwell Y, Jones MP, Phillips C, Simonsick E, Pearson JL, Wallace R (2002) Risk factors for latelife suicide: a prospective, community-based study. Am J Geriatr Psychiatry 10, 398-406. [Medline]

17) Oyama H, Koida J, Sakashita T, Kudo K (2004) Community-based prevention for suicide in elderly by depression screening and follow-up. Community Ment Health J 40, 249-63. [Medline] [CrossRef]

18) Takusari E, Suzuki M, Nakamura H, Otsuka K (2011) Mental health, suicidal ideation, and related factors among workers from medium-sized business establishments in northern Japan: comparative study of sex differences. Ind Health 49, 452-63. [Medline] [CrossRef]

19) Takada M, Suzuki A, Shima S, Inoue K, Kazukawa S, Hojoh M (2009) Associations between lifestyle factors, working environment, depressive symptoms and suicidal ideation: a large-scale study in Japan. Ind Health 47, 649-55. [Medline] [CrossRef]

20) Chin YR, Lee HY, So ES (2011) Suicidal ideation and associated factors by sex in Korean adults: a populationbased cross-sectional survey. Int J Public Health 56, 429-39. [Medline] [CrossRef]

21) Shimomitsu T, Odagiri Y (2004) The brief job stress questionnaire. Occup Ment Health 12, 25-36 (in Japanese).

22) Harada H, Suwazono Y, Sakata K, Okubo Y, Oishi M, Uetani M, Kobayashi E, Nogawa K (2005) Three-shift system increases job-related stress in Japanese workers. J Occup Health 47, 397-404. [Medline] [CrossRef]

23) Radloff LS (1977) The CES-D scale: a self-report depression scale for research in the general population. Appl Psychol Meas 1, 385-401. [CrossRef]

24) Shima S, Shikano T, Kitamura T (1985) New self-rating scales for depression. Ann Clin Psychiatry 27, 717-23 (in
Japanese).

25) Sugawara N, Yasui-Furukori N, Sasaki G, Umeda T, Takahashi I, Danjo K, Matsuzaka M, Kaneko S, Nakaji S (2011) Assessment of the Center for Epidemiological Studies Depression Scale factor structure among middle aged workers in Japan. Psychiatry Clin Neurosci 65, 109-11. [Medline] [CrossRef]

26) Wada K, Tanaka K, Theriault G, Satoh T, Mimura M, Miyaoka H, Aizawa Y (2007) Validity of the Center for Epidemiologic Studies Depression Scale as a screening instrument of major depressive disorder among Japanese workers. Am J Ind Med 50, 8-12. [Medline] [CrossRef]

27) Araya R, Gaete J, Rojas G, Fritsch R, Lewis G (2007) Smoking and common mental disorders: a populationbased survey in Santiago, Chile. Soc Psychiatry Psychiatr Epidemiol 42, 874-80. [Medline] [CrossRef]

28) Nakata A, Takahashi M, Ikeda T, Hojou M, Nigam JA, Swanson NG (2008) Active and passive smoking and depression among Japanese workers. Prev Med 46, 451-6. [Medline] [CrossRef]

29) Paperwalla KN, Levin TT, Weiner J, Saravay SM (2004) Smoking and depression. Med Clin North Am 88, 1483-94. [Medline] [CrossRef]

30) Fergusson DM, Goodwin RD, Horwood LJ (2003) Major depression and cigarette smoking: results of a 21-year longitudinal study. Psychol Med 33, 1357-67. [Medline] [CrossRef]

31) Lam TH, Stewart SM, Ho SY, Lai MK, Mak KH, Chau KV, Rao U, Salili F (2005) Depressive symptoms and smoking among Hong Kong Chinese adolescents. Addiction 100, 1003-11. [Medline] [CrossRef]

32) Sabo E, Reynolds CF 3rd, Kupfer DJ, Berman SR (1991) Sleep, depression, and suicide. Psychiatry Res 36, 265-77. [Medline] [CrossRef]

33) Krakow B, Ribeiro JD, Ulibarri VA, Krakow J, Joiner TE Jr (2011) Sleep disturbances and suicidal ideation in sleep medical center patients. J Affect Disord 131, 422-7. [Medline] [CrossRef]

34) Goodwin RD, Marusic A (2008) Association between short sleep and suicidal ideation and suicide attempt among adults in the general population. Sleep 31, 1097-101. [Medline]

35) Virtanen M, Ferrie JE, Gimeno D, Vahtera J, Elovainio M, Singh-Manoux A, Marmot MG, Kivimäki M (2009) Long working hours and sleep disturbances: the Whitehall II prospective cohort study. Sleep 32, 737-45. [Medline]

36) Nagase $Y$, Uchiyama M, Kaneita Y, Li L, Kaji T, Takahashi S, Konno M, Mishima K, Nishikawa T, Ohida T (2009) Coping strategies and their correlates with depression in the Japanese general population. Psychiatry Res 168, 57-66. [Medline] [CrossRef]

37) Christensen MV, Kessing LV (2005) Clinical use of coping in affective disorder, a critical review of the literature. Clin Pract Epidemiol Ment Health 1, 20. [Medline] [CrossRef]

38) Kawakami N, Haratani T, Araki S (1992) Effects of 
perceived job stress on depressive symptoms in blue-collar workers of an electrical factory in Japan. Scand J Work Environ Health 18, 195-200. [Medline] [CrossRef]

39) Inoue A, Kawakami N, Japan Work Stress and Health Cohort Study Group (2010) Interpersonal conflict and depression among Japanese workers with high or low socioeconomic status: findings from the Japan Work Stress and Health Cohort Study. Soc Sci Med 71, 173-80. [Medline] [CrossRef]

40) Baird JE, Zelin RC, Marxen DE (1998) Gender differences in the job attitudes of accountants. Mid Am J Bus 13, 35-42. [CrossRef]

41) Katsurada E, Sugihara Y (2002) Gender-role identity, attitudes toward marriage, and gender-segregated school backgrounds. Sex Roles 47, 249-58. [CrossRef]

42) Kjøller M, Helweg-Larsen M (2000) Suicidal ideation and suicide attempts among adult Danes. Scand J Public Health 28, 54-61. [Medline] [CrossRef]

43) Lee JI, Lee MB, Liao SC, Chang CM, Sung SC, Chiang HC, Tai CW (2010) Prevalence of suicidal ideation and associated risk factors in the general population. J Formos
Med Assoc 109, 138-47. [Medline] [CrossRef]

44) Fujino $Y$, Mizoue T, Izumi H, Kumashiro M, Hasegawa T, Yoshimura T (2001) Job stress and mental health among permanent night workers. J Occup Health 43, 301-6. [CrossRef]

45) Tanaka K, Ihara K, Iwasaki A, Muraoka Y, Otsubo T, Kamijima K (2002) Prevalence of and factors associated with depressive state in middle aged workers. Showa Univ J Med Sci. 14, 27-33.

46) Tiesman HM, Hendricks HS, Bell JL, Amandus HA (2010) Eleven years of occupational mortality in law enforcement: the census of fatal occupational injuries, 1992-2002. Am J Ind Med 53, 940-9. [Medline]

47) Grosch JW, Murphy LR (1998) Occupadonal differences in depression and global health: results from a national sample of US workers. J Occup Environ Med 40, 153-64. [Medline] [CrossRef]

48) Cho JJ, Kim JY, Chang SJ, Fiedler N, Koh SB, Crabtree BF, Kang DM, Kim YK, Choi YH (2008) Occupational stress and depression in Korean employees. Int Arch Occup Environ Health 82, 47-57. [Medline] [CrossRef] 